\title{
FANATISME FANS SEPAKBOLA TERKAIT FLAMING DAN NETIQUETTE
}

\author{
Yudha Wirawanda \\ Prodi Ilmu Komunikasi, Universitas Muhammadiyah Surakarta \\ Email : yudha.wirawanda@ums.ac.id
}

\begin{abstract}
ABSTRAK
Spectre adalah salah satu thread di forum daring Kaskus. Thread ini memungkinkan pengguna untuk melakukan flaming yang berkaitan dengan fanatisme pendukung sepakbola. Walaupun memperbolehkan prosumsi flaming, namun Spectre tetap memiliki netiquette. Penelitian ini menganalisis praktik fanatisme fans sepakbola terkait flaming dan netiquette. Penelti menggunakan teori habitus dan arena dari Bourdieu untuk menganalisis perilaku pengguna. Peneliti juga menggunakan konsep prosumsi dan netiquette untuk menganalisis data. Peneliti menggunakan metode etnografi virtual untuk menganalisis permasalahan. Peneliti berkesimpulan bahwa bentuk fanatisme dan flaming di ruang siber dibentuk juga oleh netiquette. Namun kebiasaan dan budaya fanatisme pengguna di Kaskus juga membentuk netiquette yang ada di Spectre.
\end{abstract}

Kata Kunci: fanatisme, Kaskus, habitus, netiquette, flaming, prosumsi

\section{A. LATAR BELAKANG}

KASKUS merupakan salah satu forum internet terbesar di Indonesia. KASKUS dibuat oleh Andrew Darwis dan kedua kawannya pada 6 November 1999 (Wirawanda, 2017). Pada awalnya situs ini hanya berisi berita terjemahan dari Indonesia. Namun kini KASKUS merupakan salah satu forum teramai di Indonesia. Setiap harinya jutaan akun yang terdaftar di KASKUS berinteraksi dalam berbagai subforum yang tersedia. Pengguna dapat bertukar informasi dengan pengguna lain dalam sebuah laman yang disebut thread. Aktivitas pengguna ini diawasi oleh pengguna tertentu yang ditunjuk oleh pihak Kaskus. Pengguna yang mengawasi aktivitas Kaskus tersebut disebut moderator. Setiap subforum di Kaskus memiliki moderator yang berbeda.

Salah satu subforum di KASKUS membahasa tema sepakbola. Subforum ini berisi berbagai macam thread yang membahas tema sepakbola, baik dalam negeri maupun internasional. Kita bisa membahas tim sepakbola lokal hingga tim nasional negara manapun. Salah satu thread yang ada si subforum ini adalah thread Spectre.
Semua thread di subforum kaskus mewadahi praktik fanatisme. Fanatisme sendiri merupakan rangkaian aksi yang menunjukkan suatu ekstarsi, eforia, atau kebanggaan terhadap sesuatu (King, 1997, dalam Derbaix dkk., 2014). Seorang fan merupakan individu yang memiliki minat berlebihan dan terobsesi terhadap sebuah tim, selebriti, atau musisi (Crawford, 2004: 3). Pengguna di kaskus menunjukkan praktik fanatisme ini dalam berbagai bentuk posting, termasuk juga posting yang mengandung flaming.

Flaming adalah segala teks yang di dalamnya terkandung hinaan, umpatan, atau penggunaan bahasa yang kasar (Moor dkk., 2010, dalam Elliot, 2014: 5). Aktivitas ini dilarang di Kaskus. Pengguna yang dianggap melakukan flaming oleh moderator akan diberi sanksi http://www. kaskus.co.id//53af7c05529a45c50f8b4675/ general-rules-laporan-approval-threadsoccer-room/ diakses pada 28 Oktober 2017). Sanksi yang sering diberikan adalah banned Id Kakus pengguna.

Namun di subforum Soccer ternyata aktivitas flaming diberi ruang di thread Spectre. Spectre adalah thread yang dibuat khusus oleh moderator. Thread ini dibuat 
sejak tahun 2005. Tujuan dari dibuatnya Spectre adalah agar tidak ada lagi pengguna yang melakukan flaming di berbagai thread fansclub di subforum Soccer. Adanya thread ini diharapkan oleh moderator agar tidak muncul lagi orang yang membuat identitas khusus untuk memancing keributan (http://www.kaskus.co.id/ thread/54ce2861582b2e2f7c8b456b/ spectre-soccer-room-2014-2015------part-2/ diakses pada 28 Oktober 2017).

Sebagai sebuah aktivitas di ruang siber, flaming di Spectre tidak sepenuhnya bebas. Spectre juga memiliki netiquette. Netiquette adalah berbagai aturan berkomunikasi di ruang siber. Aturan yang sering ada dalam netiquette sebuah forum atau situs adalah aturan untuk menggunakan bahasa yang sopan, pengaturan jumlah posting, hingga seberapa besar kapasitas file yang boleh diunggah (McLaughlin, Osborne, dan Smith, 1995, dalam Bell, 2004: 114). Peraturan yang ada di Spectre antara lain status pengguna dan batasan bentuk flaming.

Kaskus sendiri melarang bentuk flaming, namun memberikan pengecualian di Spectre. Spectre menjadi salah satu thread yang sering dikunjungi pengguna, salah satunya ditunjukkan bahwa thread ini hampir selalu dimasukkan dalam kategori sticky. Sticky adalah status thread yang selalu berada di bagian paling atas suatu subforum Kakus (kaskus.co.id/forum/104/ soccer-amp-futsal-room diakses pada 28 Oktober 2014). Adanya Spectre ini membuat pengguna dapat melampiaskan fanatisme yang menjurus flaming tanpa khawatir dikenai sanksi, asal sesuai dengan netiquette yang ada. Pengguna tidak hanya melakukan produksi flaming, namun juga prosumsi. Prosumsi adalah konsep ketika pengguna memproduksi sekaligus mengkonsumsi konten (Ritzer dan Jurgenson, 2010, dalam Denegri-Knott dan Zwick, 2012: 2).

Flaming merupakan bagian yang tidak terpisahkan dari fanatisme sepakbola. Namun praktik ini dilarang di banyak ranah, termasuk forum online. Kaskus sendiri melarang flaming di sembarang thread, kecuali di Spectre. Menarik untuk melihat bagaimana prosumsi flaming pengguna terbentuk di Spectre. Penelti akan menggunakan teori habitus dari Bourdieu dan konsep ruang siber untuk memahami logika pengguna terkait prosumsi flaming. Habitus dapat dijadikan rujukan untuk melihat bagaimana pengguna mempertimbangkan dan memutuskan perilaku terkait dengan nilai, hukum, dan konsekuensi. Penelitian ini menjelaskan bagaimana kaitan netiquette dan prosumsi flaming pengguna di thread Spectre Kaskus.

\section{B. TINJAUAN PUSTAKA}

Ruang siber merupakan sebuah produk budaya sekaligus salah satu faktor yang dapat membentuk budaya (Bell, 2001: 2). Ruang siber menjadi sebuah ranah yang tidak bebas nilai. Paradigma critical theory of technology melihat bahwa teknologi dapat dipakai oleh manusia untuk menciptakan atau melanggengkan dominasi. Namun teknologi juga bisa kita gunakan untuk mendestabilisasi nilai tertentu (Bakardjieva, 2005: 17). Konstruksi semacam ini semakin terlihat dalam era web 2.0. Web 2.0 adalah sebutan untuk media internet yang mendukung fasilitas riber berupa jaringan sosial, produksi dan berbagi informasi bersama, produksi konten dari pengguna, pembentukan komunitas online, difusi, dan juga konsumsi (Fuchs dkk., 2012: 3). Ruang siber juga memungkinkan bentuk komunikasi yang egaliter, sehingga pengguna biasanya memiliki kesempatan yang bersama untuk meproduksi dan mengkonsumi konten (Amin, dkk.,2018). Selain itu ruang siber juga memungkinkan pengguna untuk mempraktikkan bentuk praktik sosial yang belum pernah dilakukan di ruang offline (Wirawanda dan Wibowo, 2018). Praktik sosial tersebut termasuk juga bentuk praktik fanatisme.

Fanatisme adalah dukungan tanpa kompromi dan seringkali ekstrim dari sebuah kelompok, grup, atau partai yang bisa berawal dari sebuah ide atau opini (Vaneigem, 1978-1980, dalam 
Derbaix dkk.,2014). Fanatisme dapat juga dimaknai sebagai aksi-aksi yang menggambarkan suatu candu, eforia, atau kebanggaan terhadap sesuatu (King, 1997, dalam Derbaix dkk.,2014). Fanatisme pengguna menghasilkan praktik dukungan terhadap tim sepakbola yang didasari oleh ciri tersebut. Pengguna di Spectre mempraktikkan fanatisme ini dalam berbagai bentuk, termasuk flaming.

Pengkategorian flaming sebagai salah satu bentuk fanatisme harus dilihat secara subjektif dan juga kontekstual. Menurut David Bell (2004: 70), flaming adalah berbagai pesan dalam ruang siber yang menggunakan bahasa kasar dan dapat memancing keributan dengan pengguna lain. Flaming adalah istilah dalam dunia daring yang diberikan kepada segala perilaku pengguna yang tidak menyenangkan (Moor dkk., 2010, seperti dikutip oleh Elliot, 2014: 5). Dalam konteks budaya fanatisme sepakbola, bahasa kasar seringkali ditunjukkan antar pendukung tim sepakbola. Hal tersebut bukanlah suatu hal yang aneh praktik fanatisme sepakbola. Berbagai chant, nyanyian suporter yang berisi hinaan berbau rasial bahkan ancaman kekerasan sering kita jumpai di berbagai sudut stadion sepakbola. Menurut Matt Hills (2002, dikutip oleh Crawford: 2004), fanatisme bukan hanya label atau kategori namun merupakan praktik dan identitas. Flaming, hinaan berbau rasial dan ujaran kebencian seringkali menegaskan identitas pihak yang didukung dan memisahkan diri dari pihak yang dibenci.

Untuk menganalisis konstruksi fanatisme pengguna di Spectre, peneliti mengikuti pemahaman Sandvoss (2003) tentang teori narsisme dari Marshall McLuhan. Sandvoss (2003: 39) meminjam konsep narsisme McLuhan untuk menjelaskan hubungan fans dengan tim sepakbola yang didukung. McLuhan (1964) memberi contoh bentuk narsisme dengan memandang media sebagaisebuah ekstensiidentitas seseorang. Sandvoss beranggapan bahwa pendukung sepakbola memandang tim yang didukung sebagai ekstensi citra identitas diri. Mereka tidak hanya memandang tim sepakbola sebagai proyeksi dari rasa kegemaran saja namun juga sebagai sebuah refleksi citra diri mereka sendiri. Sandvoss juga memandang bahwa fans mencintai tim yang didukung sebagai bentuk citra identitas diri.

Peneliti juga menggunakan konsep prosumsi untuk menjelaskan praktik flaming pengguna di Spectre. Prosumsi, merupakan singkatan dari prosuksi dan konsumsi. Praktik ini ditunjukkan saat konsumen terlibat dalam memproduksi sebagian atau keseluruhan suatu hal yang dia konsumsi (Ritzer dan Jurgenson, 2010, dalam Denegri-Knott dan Zwick, 2012: 2). Ritzer (2014) juga mengemukakan bahwa prosumsi tidak harus terjadi dalam suatu waktu yang berurutan. Seorang prosumer bisa memproduksi sesuatu dalam suatu waktu dan kemudian mengkonsumsi konten atau hal tersebut pada waktu yang lain. Internet memungkinkan peleburan posisi produsen dan konsumen, sehingga menjadikan semua pengguna internet sebagai seorang prosumer (Bell, 2007: 78). $\mathrm{Hal}$ ini membuat banyak praktik prosumsi yang tidak diperkirakan atau dipraktikkan sebelumnya di ruang offline.

Penulis menggunakan teori Bourdieu mengenai habitus dan arena sebagai panduan utama untuk melihat prosumsi flaming pengguna di Spectre. Habitus bagi Bourdieu adalah suatu sistem disposisi yang berubah-ubah dan menyebar. Habitus juga dapat dipahami sebagai suatu konstruksi struktur juga berfungsi membentuk struktur tertentu (Bourdieu, 1992: 53). Habitus merupakan landasan yang membentuk praktik dan representasi. Habitus merupakan bagian yang tidak terpisahkan dari perbuatan. Habitus terbentuk dalam proses yang lama dan akan selalu berkaitan dengan sejarah seseorang dan lingkungannya. Jadi habitus bukan merupakan otoritas subjektif individu sepenuhnya atau merupakan konstruksi lingkungan sosial sepenuhnya. Habitus juga merupakan rangkaian strategi yang memungkinkan manusia menghadapi berbagai kemungkinan situasi dalam kehidupannya. Habitus sangat berhubungan dengan pengalaman masa lalu manusia dan berfungsi pada setiap saat dalam kehidupan 
manusia (Bourdieu dan Wacquant, 1992: 18). Penelitian ini hanya fokus pada aktivitas pengguna di ruang siber. Karena itu, peneliti hanya menganalisis habitus virtual pengguna yang berhubungan dengan fanatisme dan flaming.

Habitus seseorang selalu berkaitan dengan konsep arena. Arena adalah suatu jaringan atau konfigurasi dari relasi yang diposisikan agen-agen secara obyektif. Arena terbentuk dari serangkaian penempatan strategi kapital dari agenagen individu atau institusi. Kompetisi dan pertarungan dalam arena ini akan berhubungan dengan kapital yang dimiliki agen-agen di dalamnya. Kapital merupakan akumulasi aksi-aksi yang menjadi basis agen-agen. Basis akumulasi ini menjadi modal yang penting bagi agen-agen itu untuk mewujudkan praktik sosial tertentu Bourdieu dalam Bourdieu dan Wacquant, 1992: 118). Penulis akan mengutamakan kapital simbolik dari pengguna di Spectre.

Setiap agen atau institusi memiliki akses dan kepentingan tertentu dalam arena sehingga akan selalu berelasi terhadap posisi-posisi agen lain dalam arena (Bourdieu dalam Bourdieu dan Wacquant, 1992: 97). Arena merupakan ranah terjadinya konflik dan kompetisi antar agen. Konflik dan kompetisi ini terjadi antar kepentingan dan ditunjukkan lewat penempatan kapitalkapital setiap agen dalam arena. Setiap kapital ini memiliki kepentingan masingmasing untuk melanggengkan atau mendestabilisi nilai dan praktik (Wacquant dalam Bourdieu dan Wacquant, 1992: 17).

Kapital simbolik memiliki logikanya sendiri dan tidak tergantung pada akumulasi kepemilikian materi atau pengetahuan tertentu (Bourdieu dalam Bourdieu dan Wacquant, 1992: 119). Kapital simbolik merupakan rangkaian pengakuan, yang terbentuk secara institusional atau tidak, yang diperoleh agen dari sebuah grup (Bourdieu, 1991: 72). Kapital simbolik ini seringkali juga merupakan bentuk akumulasi kapital apapun yang dipakai dalam hal yang bukan merupakan kapital ekonomi (Bourdieu, 1992: 118).
Dalam menempatkan kapital dalam arena, agen selalu mempertimbahkan berbagai kemungkinan, termasuk aturan dalam arena. Aturan dalam ruang siber salah satunya adalah netiquette. Netiquette adalah rangkaian kesepakatan mengenai perilaku pengguna dan bentuk komunikasi di ruang siber (McLaughlin, Osborne dan Smith, 1995 dalam Bell, 2004: 114). Netiquette sering terbentuk secara informal dalam pergaulan di internet. Netiquette juga dapat dibentuk oleh orang yang memiliki kapasitas dan berkepentingan mengatur pergaulan di internet.

Peraturan biasanya dibentuk berdasarkan moral-moral yang diterima secara umum (Hamelink, 2000: 42). Kizza (2014: 62) menjelaskan bahwa netiquette seringkali juga mengacu pada nilai di ruang offline. Pengguna biasanya mengacu pada etiket-etiket yang mereka kenal di ruang offline. Namun netiquette juga dapat berbeda dibandingkan etiket di ruang offline. Netiquette ini dibentuk oleh kepentingan tertentu dan tidak terbentuk secara alamiah. Netiquette dalam sebuah ruang siber bergantung dalam konteks, ruang, dan kepentingan tertentu.

Netiquette juga biasanya berisi sanksi bagi pelanggarnya. Sanksi diberlakukan agar pengguna tidak mudah mengabaikan netiquette. Salah satu sanksi yang sering diberikan adalah penghapusan identitas daring pengguna. Identitas online di beberapa forum memang tidak berarti bagi pengguna, namun di sebagian forum lain dapat bermakna cukup signifikan bagi pengguna. Faktor inilah yang dapat menjadi kekuatan netiquette untuk membatasi perilaku pengguna. Teknologi internet memang memungkinkan pengguna bebas menyampaikan pesan. Namun dengan adanya pergaulan dengan pengguna lain, maka selalu ada aturan untuk membatasi perilaku di ruang siber.

\section{METODE PENELITIAN}

Penulis akan menggunakan metode netnografi untuk mengumpulkan dan menganalisis data. Bagi Robert Kozinets 
(2010) netnografi merupakan bentuk etnografi yang telah disesuaikan dengan keunikan dan kemungkinan di ruang siber. Netnografi memiliki cara-cara tertentu dalam memahami dan mengkaji fenomena di ruang siber.

Peneliti mengkaji praktik flaming di Spectre KASKUS. Thread Spectre yang dikaji merupakan part 2 tahun 2015 saja. Ada tiga pengguna di Spectre yang akan dikaji oleh peneliti. Pengguna ini aktif di Spectre selama beberapa tahun terakhir. Selain pengguna-pengguna tersebut, peneliti juga akan mewawancarai moderator KASKUS. Wawancara ini bertujuan untuk mengumpulkan data seputar netiquette dan pemberian sanksi di Spectre.

Ada tiga aspek yang dikaji dalam penelitian ini. Aspek pertama adalah Spectre sebagai suatu ruang siber. Sebagai sebuah ruang, Spectre mengandung karakter, nilai, dan peraturan yang dapat mengkonstruksi praktik pengguna. Aspek selanjutnya adalah berbagai posting pengguna. Posting pengguna dikaji untuk melihat fanatisme dan flaming pengguna di Spectre. Aspek selanjutnya adalah data wawancara dengan pengguna. Wawancara ini dilakukan untuk menggali pengalaman pengguna yang kemudian dikaitkan dengan pemahaman habitus virtual. Peneliti akan membandingkan data yang diperoleh dari observasi perilaku pengguna di Kaskus dan hasil wawancara. Perbandingan ini akan membantu dalam proses seleksi dan analisis data.

Christine Hine (2000) melihat etnografi sebagai metode yang fleksibel dan bisa disesuaikan dengan kondisi lapangan. Analisis penelitian bergantung pada permasalahan penelitian. Data penelitian ini akan diseleksi berdasarkan logika perilaku prosumsi dan kemudian dianalisis dengan menggunakan teori habitus khususnya dalam konteks ruang siber. Kozinets (2010: 119) memberi arahan agar data temuan penelitian dielaborasikan dengan tujuan dan permasalahan penelitian. Peneliti perlu menganalisis data temuan ini dengan berbagai teori yang menunjang tujuan dan permasalahan penelitian. Data yang terseleksi akan dianalisis dengan menggunakan teori habitus dan konsep netiquette.

\section{HASIL DAN PEMBAHASAN}

\section{Kontruksi Flaming di Spectre}

Pengguna menggunakan Spectre sebagai sarana mewujudkan fanatisme mereka yang berhubungan dengan flaming. Praktik ini didukung oleh kemungkinan yang dimungkinkan oleh thread Spectre dan juga oleh habitus dari pengguna. Habitus berpengaruh dalam memberikan keputusan bagi pengguna untuk memilih melakukan prosumsi di Spectre. Pengguna tidak hanya mengkonsumsi flaming dari pengguna lain, namun tergoda untuk posting di Spectre.

Flaming sudah menjadi habitus fanatisme pengguna di Spectre. Hal ini mempermudah mereka untuk memutuskan melakukan prosumsi flaming. Meminjam pemikiran Sandvoss (2003), maka pendukung sepakbola memposisikan tim sepakbola selayaknya diri mereka sendiri. $\mathrm{Hal}$ ini membuat fans memandang tim sepakbola lain sebagai ancaman eksistensi diri mereka. Saling ejek antar pendukung menjadi sebuah bentuk fanatisme untuk menegaskan eksistensi diri mereka. Praktik fanatisme ini bisa berbeda antar satu dan lainnya. Bagi pengguna Spectre, flaming dalam taraf tertentu menjadi salah satu bentuk fanatisme tersebut.

Namun beberapa pengguna juga melakukan flaming karena adanya pilihan yang disediakan Spectre. Habitus dapat dipraktikkan berdasarkan kalkulasi-kalkulasi atas pilihan yang disediakan oleh lingkungan sosial. Kalkulasi ini berhubungan dengan pengalaman dan nilai dari seseorang. Seseorang dapat mempraktikkan sesuatu berdasarkan kalkulasi yang terkait dengan berbagai faktor, seperti kemungkinan dan ketidakmungkinan; keinginan dan kebutuhan; serta kesempatan dan larangan (Bourdieu, 1992: 54). Adanya kesempatan melakukan flaming tanpa dikenai sanksi 
juga menjadi landasan kalkulasi pengguna untuk turut berpraktik di Spectre.

Pengguna memposisikan Spectre sebagai arena duel antar pendukung sepakbola. Mereka dapat merasa bebas melakukan flaming tanpa khawatir dikenai sanksi. Flaming yang dilakukan pengguna di Spectre juga lebih mudah dibalas oleh pengguna lain. Kemungkinan melakukan flaming tanpa dikenai sanksi serta adanya kesempatan saling serang ini menarik bagi beberapa pengguna.

Beberapa pengguna menyikapi flaming secara ambivalen. Mereka memandang bahwa flaming merupakan tindakan yang salah dan bisa mengganggu ketentraman. Namun di sisi lain mereka merasa bahwa flaming di Spectre merupakan sesuatu yang legal karena didukung oleh moderator, memiliki aturan, dan pengguna bisa bertarung secara jantan. Mereka juga menganggap flaming di Spectre berbeda, karena bernuansa humor dan mengundang tawa. Ketika umpatan dan hinaan dipakai dalam konteks atau ruang yang menimbulkan rasa humor atau dianggap wajar, maka cenderung akan diterima dan terus dilakukan (Jay, 2000: 148). Terjadi pembiasaan dari sebuah nilai yang membuat habitus pengguna menerima praktikflaming di Spetcre. Habitus pengguna terkait flaming mengalami perubahan dengan bentuk-bentuk budaya dan kebiasaan yang ditawarkan di Spectre. Arena dengan berbagai perangkatnya memungkinkan pengguna memutuskan praktik apa yang boleh dan tidak boleh dilakukan. Salah satu faktor yang membentuk budaya di Spectre adalah adanya rules.

\section{Rules dan Flaming}

Walau membolehkan flaming, namun Spectre juga membatasi bentuk flaming yang boleh dipraktikkan pengguna. Salah satu aturan dalam Spectre adalah mengharuskan pengguna yang ingin posting di Spectre untuk sudah ISO (kaskus. co.id/post/ 5241 afbffbca17927e000006 diakses pada 28 Oktober 2017). Istilah ISO diambil dari singkatan International Standart Organization. ISO merupakan istilah yang menunjukkan pengguna telah posting di Kakus minimal 2.000 posting. Dengan adanya syarat ini maka pengguna tidak dapat lantas membuat id baru hanya untuk melakukan flaming di Spectre. Pengguna yang belum menyandang status ISO dan nekat posting di Spectre akan dikenai sanksi.

Tidak mudah bagi pengguna untuk mencapai 2.000 posting. Hal ini bertujuan agar pengguna merasa sayang dengan id tersebut dan enggan jika diberi sanksi. Jika id ISO pengguna dikenai sanksi banned permanen, maka pengguna harus membuat id baru lalu membuat posting sebanyak 2.000 agar dapat beraktivitas di Spectre lagi.

Namun habitus pengguna akan bernegosiasi dengan netiquette ini. Beberapa pengguna mengakali aturan ini dengan membeli akun pengguna lain yang sudah menyandang status ISO. Bagi mereka, id pengguna di Kaskus bukanlah identitas mereka di ruang offline. Mereka menganggap identitas di forum merupakan identitas anonim yang bisa mereka konstruksikan kapan saja. Hal ini sesuai dengan karakter ruang siber terkait anonimitas. Ketika pengguna merasa bahwa dia anonim, maka dia lebih bebas untuk berperilaku di ruang siber karena tidak merasa ada konsekuensi offline secara langsung dari segala aktivitas mereka di internet (Bell: 2004) Jadi mereka tidak merasa terbebani jika id tersebut dikenai sanksi banned. Pengguna lain sebaliknya merasa khawatir jika id mereka yang sudah ISO dikenai sanksi. Hal ini membuat mereka berhati-hati dalam melakukan flaming di Spectre.

Kedua bentuk penyikapan terhadap netiquette tersebut berhubungan dengan habitus pengguna. Pengguna yang terbiasa menyikapi pergaulan forum online dapat mengakali aturan tersebut. Namun pengguna lain yang sudah kadung memposisikan id ISO sebagai identitas utama akan lebih berhati-hati dalam mengakali aturan. Habitus berkaitan dengan kalkulasi subjektif individu. 
Seseorang dapat mempraktikkan sesuatu berdasarkan kalkulasi yang terkait dengan berbagai faktor, seperti kemungkinan dan ketidakmungkinan; keinginan dan kebutuhan; serta kesempatan dan larangan (Bourdieu, 1992: 54). Adanya netiquette membatasi kesempatan dan memunculkan ketidakmungkinan bagi pengguna.

Pembatasan perilaku yang berkaitan dengan identitas merupakan bentuk etiket yang sudah lumrah dipakai untuk membatasi fanatisme pengguna. Harrington (1968: 38) menyebutkan bagaimana pihak keamanan di Inggris mewajibkan ketelasan identiats pendukung tim sepakbola sehingga mempermudah mereka untuk mengidentifikasi dan memberikan sanksi bagi yang melangar. Di Spectre, kejelasan identitas lewat aturan ISO ini mempermudah moderator untuk memberikan sanksi bagi pengguna yang melanggar.

Spectre adalah ruang yang memungkinkan pengguna untuk memilih melakukan flaming secara legal. Pilihan dalam arena initentu mempengaruhi habitus pengguna dalam memutuskan bertindak sesuatu. Adanya pilihan dalam arena ruang siber ini juga memungkinkan praktik sosial baru yang tidak dilakukan pengguna di ruang offline. Hal ini merupakan salah satu karakteristik yang disediakan oleh ruang siber (Wirawanda dan Wibowo, 2018). Habitus memungkinkan seseorang untuk bertindak atau tidak bertindak berdasarkan kalkulasi tertentu. Dengan adanya Spectre, maka pengguna dapat mempertimbangkan untuk melakukan bentuk fanatisme yang menjurus dlaming.

Pilihan habitus pengguna juga berhubungan dengan bagaimana mereka menyikapi rules di Spectre. Pilihan praktik fanatisme di thread ini akan berkaitan dengan srtategi pengguna dan peraturan di arena. Ada tiga pemahaman mengenai peraturan menurut Bourdieu. Pertama, peraturan dapat diartikan sebagai prinsipprinsip dasar yang diproduksi dan dikuasai agen-agen. Peraturan juga dapat dilihat sebagai pembiasaan yang secara objektif diberlakukan ketika agen berpraktik dalam arena. Peraturan juga bisa dilihat sebagai bentukan dari pengamat dan peneliti untuk menjelaskan praktik di arena yang sedang diteliti dan diamati (Bourdieu, 1990: 60-61). Strategi dalam pengertian Bourdieu terbentuk dari serangkaian praktik habitus agen-agen. Strategi muncul dari pertimbangan yang berdasarkan larangan, sanksi, dan pengalaman pengguna. Strategi tidaklah hanya dipraktikkan untuk mengikuti atau membantah aturan dalam arena, namun lebih kepada kemungkinankemungkinan yang dipilih dan dilakukan agen terkait habitusnya (Bourdieu, 1990: 62-64).

Jadi walaupun beberapa pengguna setuju dengan aturan yang ada di Spectre, namun mereka juga dapat mengakalinya. Misalnya peraturan mengenai status ISO dan tafsiran bentuk-bentuk flaming yang dibolehkan dan tidak dibolehkan. Praktik ini ditentukan oleh srtategi pengguna berdasarkan kalkulasi atau aturan dan larangan di Spectre.

Salah satu netiquette lain di Spectre adalah larangan untuk menghinda unsur fans club di Kaskus. Rules ini membuat aksi flaming yang dilakukan pengguna hanya ditujukan kepada tim sepakbola. Aturan ini akhirnya menghilangkan subjek pengguna sehingga muncul generalisasi. Jadi ketika pengguna ingin menghinda pengguna lain, dia tidak dapat menyebutkan status pengguna tersebut. Pengguna haris mengganti nama subjek pengguna dengan nama tim yang didukung. Hal ini dilakukan agar posting tidak melanggar aturan di Spectre. Praktik semacam ini memunculkan generalisasi tim sepakbola di Spectre. Semua pendukung tim tertentu akan dimasukkan ke dalam satu kubu. Praktik ini membentuk dan mereproduksi fanatisme di Spectre. Jadi ketika ada satu pengguna yang mendukung tim $A$ berselisih dengan pengguna lain yang mendukung tim $B$ akan memunculkan bentukpermusuhan antara kedua tim tersebut di Spectre, padahal secara tradisi fans kedua tim tersebut tidak bermusuhan di ruang lain. Konstruksi oposisi di Spectre ini juga diakibatkan bentuk ekstensi identitas pendukung 
sepakbla. Praktik generalisasi di Spectre membuat identitas individual melebur dalam satu identitas fans. Ketika netiquette Spectre melarang penggunaan nama fans klub, maka identitas itu melebur ke dalam identitas tim sepakbola yang didukung.

Adanya netiquette ternyata berpedan dalam habitus pengguna di Spectre. Pengguna akhirnya mempertimbangkan faktor rules di Spectre untuk melakukan prosumsi flaming. Adanya konsistensi dan pengawasan rutin dari moderator juga memungkinkan rules di Spectre selalu diperhatikan oleh pengguna. Pengguna lain di Spectre juga senantiasa mengingatkan adanya rules ini kepada pengguna lain. Terjadi reproduksi nilai yang ada di arena Spectre. Hal ini akhirnya mengkonstruksi bentuk fanatisme dan flaming yang diprosumsikan pengguna di Spectre.

\section{E. KESIMPULAN DAN SARAN}

Netiquette yang ada di Spectre membentuk karakteristik flaming yang dilakukan pengguna. Budaya fanatisme pengguna di Kaskus juga membentuk netiquette yang diberlakukan di Spectre. Habitus pengguna menentukan pilihan mereka untuk melakukan prosumsi flaming di Spectre. Habitus ini juga terkait dengan budaya dan arena yang ada di Spectre. Penelitian ini hanya fokus pada habitus virtual pengguna, sehingga penelitian selanjutnya dapat mengembangkan fokus penelitian pada habitus offline dari pengguna.

\section{DAFTAR PUSTAKA}

Amstrong, Gary dan Richard Giulianotti. 2001. Fear and Loathing in World Football. Oxford: Berg.

Bakardjieva, Maria. 2005. Internet Society: The Internet In Everyday Life. London: SAGE Publications.

Bell, David. 2004. Cyberculture: The Key Concepts. London: Routledge.

Bourdieu, Pierre dan Loic J.D. Wacquant. 1992. An Invitation to Reflexive Sociology. Cambridge: Polity Press.

Bourdieu, Pierre. 1990. In Other Words. Stanford: Stanford University Press.

Bourdieu, Pierre. 1991. Language and Symbolic Power. Cambridge: Polity Press.

Bourdieu, Pierre. 1995. Outline of A Theory of Practice. Cambridge: Cambridge University Press.

Bourdieu, Pierre. 1993. Sociology in Question. London: SAGE Publications.

Bourdieu, Pierre. 1993. The Field of Cultural Production. New York: Columbia University Press.

Bourdieu, Pierre. 1992. The Logic of Practice. Stanford: Stanford University Press.

Brown, Adam (ed.). 1998. Fanatics! Power, Identity and Fandom in Football. London: Routledge.

Crawford, Garry. 2004. Consuming Spor: Sport, Fans, and Culture. London: Routledge

Foer, Franklin. 2006. Memahami Dunia Lewat Sepakbola: Kajian Tak Lazim Tentang Sosial Politik Globalisasi. Serpong: Marjin Kiri

Fuchs, Christian., Boersma, Kees., Albrechtslund, Keers., dan Marisol Sandoval (ed.). 2012. Internet and Surveillance: The Challenges of Web 2.0 and Social Media. London: Routledge. 
Hamelink, Cees J. 2000. The Ethics of Cyberspace. London: SAGE Publications.

Harrington, J.A. dkk,. 1968. Soccer Hooliganism: A Preliminary Report. Bristol: John Wright \& Sons Ltd.

Hills, Matthew. 2002. Fan Cultures. London: Routledge.

Hine, Christine (ed.). 2005. Virtual Methods: Issues In Social Research on the Internet. Oxford: Berg.

Hine, Christine. 2000. Virtual Etnography. London: SAGE Publications.

Jay, Timothy. 2000. Why We Curse: A Neuro-Psycho-Social Theory of Speech. Philadelphia: John Benjamins Publishing.

Kellner, Douglas (ed.). 2006. Media and Cultural Studies. Victoria: Blackwell Publishing.

Kizza, Joseph Migga. 2014. Computer Network Security and Cyber Ethics. North Carolina: McFarland \& Company.

Kozinets, Robert V. 2010. Netnography: Doing Etnographic Research Online. London: SAGE Publications.

McLuhan, Marshall. 1994. Understanding Media: The Extensions of Man. Massachusetts: MIT Press.

Ritzer, George. 1997. Postmodern Social Theory. New York: The McGraww-Hill Company.

Ritzer, George. 1998. The McDonaldization Thesis: Explorations and Extensions. London: SAGE Publications.

Rooksby, Emma. 2001. E-mail and Ethics: Style and Ethical Relations in Computer-Mediater Communications. London: Routledge.

Sandvoss, Cornel.2003. A Game of Two Halves: Football Fandom, Television and Globalisation. London: Routledge.

Saukko, Paula. 2003. Doing Research in Cultural Studies: An introduction to classical and new methodological approaches. London: SAGE Publications.

Shea, Virginia. 1997. Netiquette. San Francisco: Albion Books.

\section{Artikel :}

Amin, Khoirul, Mohamad Dziqie Aulia Alfarauqi, Khusnul Khatimah. 2018. Social Media, Cyber Hate and Racism. Surakarta: Jurnal Komuniti. Vol. 10/ No.1.

Bourdieu, Pierre. 1973. Cultural Reproduction and Social Reproduction. Diunduh dari https://edu301s2011.files.wordpress.com/2011/02/cultural-reproduction-and-socialreproduction.pdf

Denegri-Knott, Janice dan Detlev Zwick. 2012. Tracking Prosumption Work on eBay : Reproduction of Desire and the Challenge of Slow Re-McDonaldization.

Derbaix, Christian., Decrop, Alain., dan Olivier Cabossart. Colors and Scarves: The Symbolic Consumption of Material Pissessions by Soccer Fans

Elliot, T.P., Flaming and Gaming: Computer-mediated-communication and Toxic Disinhibition. Bachelor Thesis: University of Twente.

Moor, Peter J. 2007. Conforming to the Flaming Norm in the Online Commenting Situation. 
Ritzer, George dan Nathan Jurgenson. 2010 Production, Consumption, Prosumption: The nature of capitalism in the age of the digital 'prosumer'.

Ritzer, George. 2014. Prosumption: Evolution, revolution, or eternal return of the same?.

Ritzer, George.,Dean, Paul dan Nathan Jurgenson. 2012 The Coming of Age of the Prosumer.

Wirawanda, Yudha. 2017 "Prosumption Flaming Fans Sepakbola Virtual" dalam Sukmono, Gita Filosa dan Nurudin (Editor). Komunikasi Berkemajuan dalam dinamika Media dan Budaya. Yogyakarta: Buku Litera.

Wirawanda, Yudha dan Tangguh Okta Wibowo. 2018. Twitter: Expressing Hate Speech Behind Tweeting. Yogyakarta: Profetik Jurnal Komunikasi. Vol.11/No.01/ Aprill 2018.

\section{Situs :}

http://id.kaskuspedia.wikia.com/wiki/Istilah_di_kaskus

http://www.kaskus.co.id/forum/104/soccer-amp-futsal-room

http://www.kaskus.co.id/post/5241afbffbca17927e000006

http://www.kaskus.co.id/thread/53af7c05529a45c50f8b4675/general-rules-laporanapproval-thread-soccer-room/

http://www.kaskus.co.id/thread/54ce2861582b2e2f7c8b456b/Spectre-soccer-room-20142015------part-2/

support. kaskus.co.id/ about/sejarah_kaskus.html 